\title{
Dipyridine copper chloride catalyzed coumarin synthesis via Pechmann condensation under conventional heating and microwave irradiation
}

\author{
B. Rajitha ${ }^{a}$, V. Naveen Kumar ${ }^{a}$, P. Someshwar , J. Venu Madhav ${ }^{a}$, P. Narsimha Reddy, \\ and Y. Thirupathi Reddy \\ ${ }^{a}$ Department of Chemistry, National Institute of Technology, Warangal-506009, India \\ ${ }^{b}$ College of Pharmacy Kentucky University, Lexington, USA \\ E-mail: rajitabhargavi@yahoo.com
}

\begin{abstract}
Dipyridine copper chloride is used as an efficient catalyst in the Pechmann condensation reaction of phenols with ethyl acetoacetate, in solvent-free media leading to the formation of coumarin derivatives using both conventional heating and microwave irradiation in excellent yields with good purity.
\end{abstract}

Keywords: Coumarin, dipyridine copper chloride, pechmann condensation, solvent free, microwave irradiation

\section{Introduction}

The synthesis of coumarins and their derivatives has attracted considerable attention from organic and medicinal chemists for many years as a large number of natural products contain this heterocyclic nucleus. They are widely used as additives in food, perfumes, cosmetics, pharmaceuticals $^{1}$ and optical brighteners ${ }^{2}$ and dispersed fluorescent and laser dyes ${ }^{3}$. Thus the synthesis of this heterocyclic nucleus is of much interest. Coumarins have been synthesized by several routes including Pechmann, ${ }^{4}$ Perkin, ${ }^{5}$ Knoevenagel, ${ }^{6}$ Reformatsky ${ }^{7}$ and Wittig ${ }^{8}$ reactions.

A valuable method for the synthesis of coumarins is the Pechmann reaction, of phenols, using concentrated sulfuric acid as the catalyst. ${ }^{9}$ By-products are formed and the reaction needs a long time, and introduces corrosion problems. ${ }^{10}$ For these reasons there have been some attempts to find alternative environmentally benign synthetic routes. Nafion- $\mathrm{H},{ }^{11}$ amberlyst $15,{ }^{12}$ montmorillonite clay, ${ }^{13}$ and other solid acids ${ }^{14}$ have been employed for this purpose in the Pechmann condensation. Some organic acids and metallic Lewis acids are also examined in this transformation. ${ }^{15}$ Although these methods are suitable for certain synthetic applications, many of these procedures are associated with one (or more) disadvantages such as expensive or corrosive 
reagents, long reaction time, tedious workup, and low selectivity. Large amounts of solid supports result in the generation of a large amount of toxic waste. Pechmann reactions have also been conducted in chloroaluminate ionic liquids. ${ }^{16}$ However in the case of the chloroaluminate ionic liquid method, it requires the use of $\mathrm{HCl}$ for quenching the reaction mixture, thus making the process costly and environmentally hazardous. Consequently there is scope for further development of milder reaction conditions, increased variation of the substituents in both components and better yields.

\section{Results and Discussion}

In view of the current trust in catalytic processes, there is merit in developing a truly catalytic method for the formation of 4-substituted coumarins. Now, we have found that an analogous condensation reaction can be conveniently performed under neutral and mild conditions in the presence of a catalytic amount of $\mathrm{CuPy}_{2} \mathrm{Cl}_{2} \cdot{ }^{17}$ Because of the presence of two pyridine rings, the electron deficiency increases on the nitrogen so it efficiently acts as a Lewis acid. ${ }^{18}$ The versatility of copper dipyridine dichloride encouraged us to carry out the von Pechmann reaction under benign reaction conditions. This is a novel, one-pot condensation that not only preserves the simplicity of the Pechmann condensation reaction but also consistently produces excellent yields of the coumarin derivatives and greatly decreases environmental pollution. In the conventional method (Method A) different phenols and ethyl acetoacetate were heated under reflux in the presence of dipyridine copper chloride to afford the products in 30-135 min. As part of our ongoing work with microwave irradiation, different phenols were heated under solvent free conditions with ethyl acetoacetate in the presence of dipyridine copper chloride in a microwave oven ( Method B) for the appropriate time (Table 1 ) to yield the desired products.<smiles>[R]c1ccc2oc(=O)cc(C)c2c1</smiles>

\section{Scheme 1}


Table 1. Dipyridine copper catalyzed synthesis of coumarins

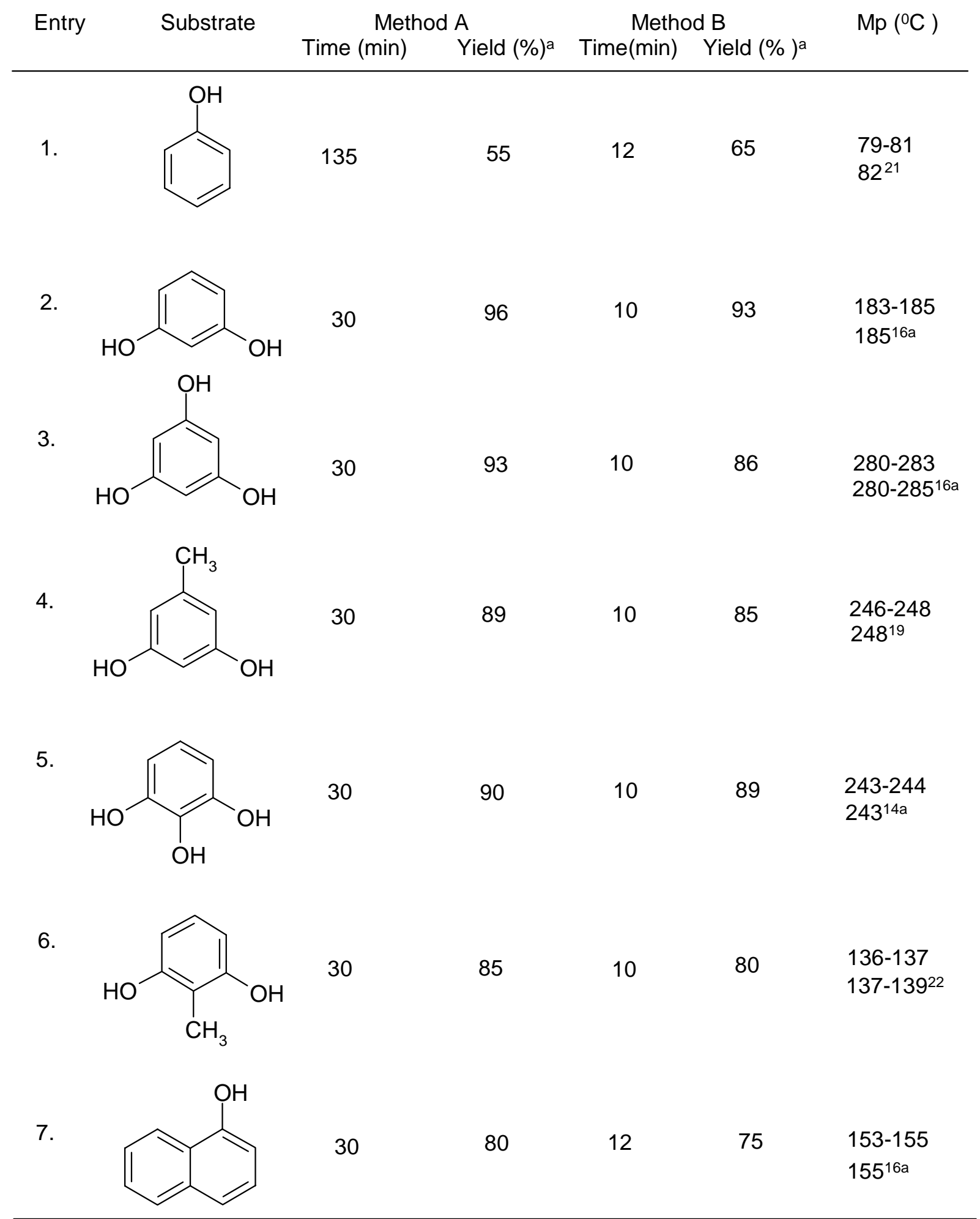

${ }^{\mathrm{a}}$ Yields refer to pure products and all products were characterized by comparison of their mp, IR, ${ }^{1}$ HNMR spectra with those of authentic samples 
For most of the substrates, the reaction time is reduced drastically even at ambient conditions in contrast to reported methods, ${ }^{19,20}$ with an excellent yield of the coumarins. Substrates (entries 2-6) having electron-donating groups in the para position to the site of electrophilic substitution gave maximum yields under mild reaction conditions in a short period of time. Phenol required a higher reaction temperature and a longer reaction time, as no electrondonating group is present.

\section{Experimental Section}

Conventional method (method A). A mixture of the phenolic compound 1 (10 mmol) and ethyl acetoacetate $(1.3 \mathrm{~g} 10 \mathrm{mmol})$ was heated under reflux in the presence of dipyridine copper chloride (10 mmol ) for the appropriate time (TLC). The reaction mixture was then cooled to room temperature and was poured onto crushed ice (50 g) and stirred for 5-10 min. The resultant product was collected by filtration under suction, washed with ice cold water $(40 \mathrm{ml})$ and then recrystallized from hot ethanol to afford pure coumarins $\mathbf{3}$ as colorless prisms.

Microwave method (method B). To a mixture of the phenolic compound (10 mmol) and ethyl acetoacetate (1.3g $10 \mathrm{mmol})$, dipyridine copper chloride $(10 \mathrm{mmol})$ was added and the mixture was inserted in a microwave oven (BPL, 800T model) and heated at $450 \mathrm{~W}$ for the appropriate time (TLC). After completion, the reaction mixture was cooled to room temperature was poured into crushed ice (50 g) and stirred for 5-10 min. The resultant product was collected by filtration under suction, washed with ice cold water $(40 \mathrm{ml})$ and then recrystallized from hot ethanol to afford pure coumarins $\mathbf{3}$ as colorless prisms.

\section{References}

1. O’Kennedy, R.; Thornes, R. D. Coumarins: Biology, Applications and mode of action; John

2. Wiley \& Sons: Chichester, 1997.

3. Zabradnik, M. The Production and Application of Fluorescent Brightening Agents; John Wiley \& Sons: New York, 1992.

4. Murray, R. D.; Mendez, J.; Brown, S. A. The Natural Coumarins: Occurrence, Chemistry and Biochemistry; John Wiley \& Sons: New York, 1982.

5. Von Pechmann, H; Duisberg, C. Ber. 1884, 17, 929.

6. Johnson, J. R. Org. React.1942, 1, 210

7. Jones, G. Org. React. 1967, 15, 204

8. Brafola, G.; Fringuelli, F.; Piermatti, O.; Pizzo, F. Heterocycles 1996, 43, 1257.

9. Shringer, R.L Org. React. 1942, 1, 1.

10. Yavari, I.; Iiekmat-Shoar, R.; Zonouzi, A. Tetrahedron Lett, 1998, 39, 2391. 
11. Horning, E. C. in Organic synthesis, Vol. III, Wiley, New York, 1955, 281.

12. Laufer, M. C.; Hausmann, H.; Holderich, W. F.; J. Catal. 2003, 218, 315.

13. Chaudhari, D. A. Chem. Ind., 1983, 568.

14. Gunnewegh, E.A.; Van Hoefnagel, A. J.; Bekkum, H. J. Mol. Catal. A: Chem., 1995, 100, 87.

15. Benyaram, M. R.; Vangala R. R.; Giridar, D. Synth. Commun, 2001, 31, 3603. (b) Hoefnagel, A. J.; Gunnewegh, E. A.; Downing, R. S.; Van Bekkum, H. J. Chem. Soc. Chem Commun, 1995, 225.

16. Sigino, T.; Tanaka, K. Chem. Lett, 2001, 30, 110. (b) Singh, P. R.; Singh, D. U.; Samant, S. D. Synlett, 2004, 1909. (c) Bose, D. S.; Rudradas, A. P.; Babu, M. H. Tetrahedron Lett, 2002, 43, 9195. (d) Bahekara, S. S.; Shindeb, D. B. Tetrahedron Lett, 2004, 45, 7997. (e) Smitha, G.; Reddy, C. S. Synth .Commun, 2004, 34, 3997.

17. Khandekar, A. C.; Khadilkar, B. M. Synlett, 2002, 152. (b) Potdar, M. K.; Mohile, S. S.;Salunkhe, M. M. Tetrahedron Lett, 2001, 42, 9285. (c) Gu, Y.; Zhang, J.; Duan, Z.; Deng, G. Adv. Synth. Catal, 2005, 347, 512.

18. Duntitz, J. D. Acta Cryst. 1957, 10, 307.

19. Naveen Kumar, V.; Someshwar, P.; Thirupathi Reddy, Y.; Narasimha Reddy, P.; Rajitha, B. J.Het. Chem, 2005, 42, 1017.

20. Sethna, S.; Phadke, R. Org. React. (New York) 1953, 7, 1.

21. Russel, A.; Frye, J. R. Org. Synth. 1941, 21, 22.

22. Abram, N. B.; Jack, D.; William, L. W. J. Med. Chem. 1986, 29, 1094.

23. Woods, L. L.; Sapp, J. J. Org. Chem. 1962, 27, 3703. 